and when for some reason pregnancy is of especially great importance to the woman, abdominal enlargement and other symptoms follow the amenorrhoea. Diaphragmatic spasm seems to be the most plausible theory of the cause of the distension because of the rapid effect of anaesthesia. If diagnosis cannot be made clinically with certainty, radiograms and Friedman tests will show conclusively whether or not the woman is pregnant. It is important to bear in mind the possibility of pseudocyesis in any atypical "pregnancy" for most mistakes arise at the present day because this diagnosis is not considered. Anaesthesia is a valuable combined diagnostic and therapeutic aid. If the patient still believes herself to be pregnant after the anaesthetic treatment along psychological lines should be given a trial.

\section{REFERENCES}

I. Bivin, G. D., and Klinger, P. (I937), Pseudocyesis.

2. BERKELEY, C. (1922), Midwifery by Ten Teachers.

3. JOHNSTONE, R. W. (I932), Textbook of Midwifery.
4. Kerr, J. M., et al. (1923), Combined Textbook of Obstetrics and GynaeA cology.

5. HalbaN, J. (I9I5), Zentralb. f. Gynakologie, 39, 409.

6. WAGNER (1928), Zentralb. $f$. Gynakologie, 52, Io.

7. Macomber, D. (1932), J. Amer. Med. Ass., 98, 4, 304.

8. WHictics.

9. JANA, A. P. "A Case of Pseudocyesis Followed by True Pregnancy. (D) Ind. Med. Gaz., Aug. 1934, 445.

ro. DE LEE, J.

II. MACGREGOR.

Quoted from Bivin, G. D. and Klinger, P.:

(a) Good, J. M. (1823), A Physiological System of Nosology with Corrected and Simplified Nomenclature, 443.

(b) PAjot, C. (I882), Travaux d'obstetrique et de gynecologie; preced $\frac{\complement}{\mathrm{s}}$ d'elements de pratique obstetricale, 679.

(c) HARveY, W. (1847), Works of William Harvey. Translation by Willif 624 .

(d) Mauriceau, F. (I72I-8), Traité des maladies des femmes grossesses de celles qui sont accouchees. 6 th ed. 555 .

(e) Chapman, E. M. (1864), "Spurious Pregnancy, its Symptoms, Diagnosis, and Treatment, with a Record of Cases," Amer. Med. Times, 9, 50, 62 .

(f) Simpson, J. Y. (187r), Clinical Lectures on the Diseases of Women. Edit. A. L. Simpson, Vol. III.

(g) Tichenor, E. J. (1879), "Phantom Tumour or What Is It." Obstw Gaz. 2, 7-13.

(h) Haltain, F. W. (I8gr), "Spurious Pregnancy," Amer. J. Med. Se $101,342-5$. (i) BouchACOURT, A. (I892), "Sur la grossesse nerveus au imaginaire,
Lyon Med., 69, I92 1 .

(j) JANET, P. (I9I I), L'etat mental des hysteriques. and ed. 708.

(k) MEYNT J (I907), "Du diagnostic de la grossesse reveuse," Marseill Med. 44, 4 Med., 44, 4I7-529. (1857), Signs and Symptoms of Pregnancy, $568 \mathrm{~N}$

(l) Montgomery, F. W. (I857), Signs and Symptoms of Pregnancy, 568 .

\title{
MODERN TREATMENT OF VINCENT'S INFECTION
}

\section{Fellow of the Royal Academy of Medicine in Ireland. Fellow of the Royal Society of Tropical Medicing}

It is a true estimate to say that the incidence of Vincent's Infection has increased to an alarming extent during recent years. We must recognise this disease as a grave menace to the health of the nation, and that at a time when health, strength and vigour are more than ever necessary for the work of restoration and reconstruction. Never before was the national need so great for healthy bodies and healthy minds. As a nation we are suffering from under-nourishment, unhygienic and inadequate housing conditions and war-strain. It is apparent in the poor physique and the lack of stamina so painfully evident in modern life. Capacity for resisting infection is today at a low ebb.

The incidence of Vincent's Infection is particularly heavy amongst industrial workers; and this is probably due to transmission of infection by imperfectly cleansed spoons, forks and drinking vessels in Works Canteens. This fruitful source of infection should be first on the list for attack in any organised and effective campaign. Steps should be taken to bring home to workers the gravity of the disease, the importance of avoiding infection and of obtaining skilled treatment in the early stages. It is unfortunate that the general public does not at all appreciate the gravity of Vincent's Infection, or its far-reach systemic consequences. The mere matter of inflamed condition of the gums seems to most $\vec{F}$ persons a comparatively trivial thing, with the unhappy result that they do not seek advice an $\Phi$ treatment until the disease is in its advance ${ }^{\circ}$ stages with most of its evil sequelae in full playo This may be explained by the fact that in th $\vec{g}$ earlier stages the two factors which usually impeB people to seek medical or dental treatment-paip and impairment of function-are absent. The individual is not the only sufferer by reason this procrastination; the community suffers too? for the infected person is a source of potentia danger, since he infects every drinking-vesset. spoon or fork that he uses. Early diagnosis an early treatment are of the utmost importance for the patient's own sake, to prevent the develops ment of remote systemic consequences, and alser to check the spread of the disease. May I repeat. that Vincent's Infection is today a grave menaç् to the public health? I base that considered opinion on the experience of a large and buspo dental practice which deals with a considerable number of industrial workers in an importanf centre of industry. The number of those whक्षे 
seek treatment for this disease is steadily increasing.

Here is a field for team-work by the medical and dental professions; and I make an appeal for more of that team-work and more co-operation. The medical practitioner probably sees far more cases of incipient Vincent's than we do since, as I have said, people rarely come to us until the disease is far advanced. Our trouble in the dental profession is that we seldom see these cases in the early stages, and our constant lament isif only I had got this case sooner! So I would earnestly appeal to medical practitioners either to treat these incipient cases or refer them to us for treatment. Then, indeed, we might go a long way towards reducing the incidence of a disease which is threatening the health of the community. I am sure that if this disease with all its evil consequences is to be reduced to a minimum it can only be done by cordial and hearty co-operation between the two professions whose first care is the health of that community. Only by pooling our knowledge'can we get the best results and, in the hope that it may be of help, I gladly pass on the dental view and the methods which, in my own practice, are giving good results.

We view this infection in the light of the hypothesis of focal infection; that an infection, often latent, in one part of the body can and does cause infections in other and often remote parts of the body. Dental infections, such as periapical or parodontal disease, can be a factor in producing disease in quite another part of the body. The dental infection is a focus from which bacteria and toxins pass into the blood-stream and are conveyed to all parts of the body. This is what happens in periapical infection. In parodontal disease the bacteria pass directly to the stomach. The oozing from the gums of septic matter, forced out by mastication, contaminates the food in the mouth, and when this contamination is carried to the stomach it sets up gastric trouble, infecting the duodenum and intestines and in some cases causing duodenal ulcer and chronic appendicitis.

The whole subject of general diseases due to focal infection would call for a large volume if one were to essay anything like adequate treatment of so vast a subject. It will suffice to mention some of the more common diseases which may be caused or aggravated by dental sepsis:-various diseases of the stomach, intestines and gall bladder, arthritis and fibrositis, infective endocarditis, arterio-sclerosis, anaemia, many diseases of the nervous system, some forms of skin disease and ocular conditions such as iritis, irido-cyclitis, keratitis and optic neuritis. A formidable list, truly; but there is more; the late Frank Steadman, of honoured memory, considered that dental sepsis is a factor of importance in the causation of cancer of the alimentary tract, and he was now mean authority on the subject. At any rate, if dental sepsis be considered as a chronic irritation the reflection does start a significant train of thought when seeking to correlate that with the aetiology of malignant disease.

The ways of treating Vincent's Infection areo legion; many of them will give admirable resultso in the early stages of the disease. At that phasew a treatment that is as effective as it is simple is tod instruct the patient to brush the teeth and gums $\mathrm{s}_{\mathrm{o}}$ night and morning with warm water and common ${ }^{\infty}$ salt, and to follow this by spending five minutes? by the clock rinsing the mouth thoroughly with equal parts of hydrogen peroxide and hot water. This can be supplemented by allowing two or three 5-gr. tablets of potassium chlorate to dissolve 3 . slowly in the mouth three times a day. Of otheris early treatments I found sodium hypochlorite to N give moderately good results, but ascorbic acidN was uncertain and unpredictable.

It has always seemed to me that to attain $\mathbb{C}_{0}$ success in treating advanced cases of Vincent'so Infection one must not rest content with loc: $\mathrm{Sl}_{-}$ treatment alone, for that is only half-perhas less than half-of the battle. It may well that failure to cope adequately with some formas of dental sepsis can be attributed to inadequate development of a systemic line of attack reinforcigg? a local one.

I feel that at this point I should apologise the inordinate use of the first person singular; bat? I am outlining the treatment which I use in my? work and which I have more or less developed by experiment. Criticism must be directed at meฏ alone if it does not work!

I treat all advanced cases with either penicillin $\stackrel{\mathbb{2}}{\Rightarrow}$ or the sulphonamides, using the penicillin only for cases so virulent and foul that they appear at $\frac{}{\sigma}$ first sight to be utterly hopeless.

In all cases I remove deposits from the teeth with all possible care and gentleness.

The penicillin treatment is carried out as follows. A preliminary local injection of 20,000 units is 3 . made. This is usually divided up into two injections of 5,000 in the upper jaw and two similar injections in the lower. Daily injections of $10,000_{0}^{\circ}$ units similarly divided on each of the three following days. Further injections are not likely to beo needed, but if they are they can be given. On= the second day and for five or six days following the patient takes one penicillin lozenge (500 units) three times a day.

The sulphonamide treatment is as follows: For ${ }^{\mathrm{N}}$ local treatment prepare a paste by crushing to $a^{2}$ fine powder one or two sulphathiazole (M \& $\mathrm{B}$ C $760)$ tablets and adding to this powder sufficient 
sulphathiazole ointment to form a fairly stiff paste. The formula for this ointment is:-

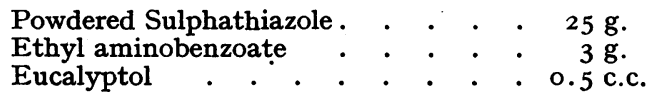

Add equal parts of petrolatum and lanolin to make roo $\mathrm{g}$.

This paste is packed into pockets, well under loose gum margins and into the interdental spaces back and front. When the packing is complete it can be sealed into place by drying the gums and teeth and painting over with Portex Medicated Plastic Skin. For the next three or four days the dressing of the previous day should be removed, the mouth well rinsed with peroxide and then with warm water that has boiled and been allowed to cool. A new dressing is applied and sealed in as before. After three or four days it is sufficient to apply the treatment on alternate days until the condition has cleared. A steady and progressive improvement should be noticeable from the first dressing.

The. systemic treatment is as follows:-An initial dose of $4 \mathrm{~g}$. of sulphathiazole, and thereafter I g. every four hours for seven days. While taking these tablets patients must be warned not? to eat cheese, onions or eggs and not to take Epsom salts. They must drink plenty of watero and must adhere rigidly to punctuality in takings the dose every four hours, even to being wakened? during the night strictly on time.

I do not wish to make any extravagant claims for this treatment; but I do claim that it has giveno and is giving good results, even in most virulento cases.

As yet we have insufficient data for an accurated evaluation of local sulphonamide therapy. Much of that which we have is based on the presence or ${ }^{\text {s }}$ absence of pain, the healing agent, the state of theo tissues and so on. These are not easy to analyse. $\overrightarrow{.}$ Then again, other drugs may be used at the same్t time, and all this makes accurate evaluationo difficult. There is still experimental work to bes done to determine the precise healing effects of the sulphonamides, and dosage in local application needs much more accurate definition, for we arew hardly beyond an empirical stage. It is quite possible, as Sinclair and Barker pointed out early: in the history of sulphonamide therapy, that ano excessive dose of the drug may delay rather that? promote healing.

\section{TOXAEMIA OF PREGNANCY}

\section{being}

Observations on the Prognosis, Maternal and Foetal, in Pre-Eclampsia and Eclampsia Made Over a Period of Twenty Years in the Same General Practice.

$$
\text { By L. N. Jackson, M.C. D.M. (Oxford) }
$$

By pre-eclampsia is meant a toxaemia usually, though not invariably, manifesting itself in the latter half of pregnancy and characterised clinically by a more than physiological rise in the blood pressure, the presence of albumen in the urine and the appearance of oedema, "renal" in distribution.

The incidence of pre-eclampsia clearly varies in different localities, the average figure usually given for the British Isles being in the region of 3 per cent. In a series of 1,267 consecutive pregnancies seen in this practice during the past 20 years pre-eclampsia was noted 40 times; once in each of 33 patients, twice in three, and once in a patient who had had eclampsia with two previous pregnancies.

The figure $\mathrm{r}, 267$ comprises $\mathrm{I}, 0 \mathrm{I}_{4}$ labours attended by one or another partner of the practice, together with 253 cases confined by district midwives after ante-natal examination by a member of the firm. The incidence of pre-eclampsia in this series is thus approximately $3 \cdot 2$ per cent. In this same series the incidence of eclampsia was only three, in two of which there was a history of a previous attack This tallies reasonably well with the usual text-o book figure for eclampsia of I per 580 pregnancies and is almost certainly accurate, since eclampsia could scarcely escape the notice of a Gamp, still less of a district midwife, and would certainly be referred to a doctor.

\section{Analysis of 40 Cases of Pre-eclampsia}

All these cases were treated secundum artem as soon as diagnosed and of them 22 occurred in primigravidae, 18 in multiparae. Pre-eclampsia was seldom observed among the younger mothers, $\frac{}{0}$ the average age of the whole group being nearly 30 and of the primigravidae, 29.

Seventeen patients were 30 years old or more at the time of their first attack. The youngest patient was 2I, the oldest 42 . Though twins are ${ }^{\omega}$ relatively common in this county pre-eclampsia associated with twins occurred only once in this? series. 